\title{
Formas de Uso do Solo No INVERno e sua Relação Com a Infestação de Plantas Daninhas em Milho (Zea mays) Cultivado EM SUCESSÃO
}

\author{
Different Winter Soil Uses and their Relation With Weed Infestation in Maize (Zea mays) in \\ Succession
}

BALBINOT JR., A.A. ${ }^{2}$, MORAES, A. ${ }^{3}$, PELISSARI, A. ${ }^{3}$, DIECKOW, J.. e VEIGA, M. ${ }^{5}$

\begin{abstract}
RESUMO - Na região Sul do Brasil há carência de opções economicamente viáveis para uso do solo durante os meses de maio a setembro. Nesse periodo, uma alternativa é o cultivo de pastagens em sistema de integração lavoura-pecuária. O objetivo deste trabalho foi avaliar o efeito de diferentes formas de uso do solo no inverno sobre a infestação de plantas daninhas na cultura de milho semeada em sucessão. Foram conduzidos dois experimentos entre maio de 2006 e abril de 2007. Avaliaram-se cinco formas de uso do solo no inverno: 1) consórcio de aveia-preta + azevém + ervilhaca + trevo-vesiculoso manejado sem pastejo e sem adubação nitrogenada (consórcio cobertura); 2) o mesmo consórcio, com pastejo e com adubação nitrogenada de cobertura - $100 \mathrm{~kg} \mathrm{ha}^{-1}$ de N (pastagem com N); 3) o mesmo consórcio, com pastejo e sem adubação nitrogenada (pastagem sem N); 4) nabo forrageiro, sem pastejo e sem adubação nitrogenada (nabo forrageiro); e 5) pousio, sem pastejo e sem adubação nitrogenada (pousio). A utilização do solo no inverno com cultivo consorciado de espécies para cobertura do solo permite alta produção de palha para proteção do solo no verão, reduzindo a infestação de plantas daninhas. Nas condições em que foi realizado o trabalho, o uso do solo no inverno com pastagens anuais permite elevada infestação de plantas daninhas no verão, pois a quantidade de palha remanescente é pequena.
\end{abstract}

Palavras-chave: integração lavoura-pecuária, manejo cultural de plantas daninhas, plantio direto.

\begin{abstract}
Economically viable alternatives for winter soil use in southern Brazil are scarce. During this period, pasture cultivated under crop-livestock system is an alternative. The objective of this study was to evaluate the effect of different winter soil uses on weed infestation in maize cultivated in succession. Two experiments were carried out from May, 2006 to April, 2007. Five alternatives of winter soil use were investigated: 1) multi-cropping with black oat + ryegrass + vetch + arrow leaf clover without grazing and nitrogen fertilization (multi-cropping cover);2) the same multi-cropping, with grazing and nitrogen fertilization, $100 \mathrm{~kg} \mathrm{ha-1}$ of $N$ (pasture with $N$ ); 3) the same multi-cropping, with grazing and without nitrogen fertilization (pasture without N); 4) oil seed radish, without grazing and nitrogen fertilization (oil seed radish); and 5) natural vegetation, without grazing and nitrogen fertilization (fallow). Cover crop in the winter, cultivated without grazing, produces a high amount of straw, reducing weed summer infestation. Under the experimental conditions, winter soil use with pasture allows high weed summer infestation, due to the low amount of straw that stays on the soil.
\end{abstract}

Keywords: crop-livestock interaction, weed cultural management, no-tillage.

1 Recebido para publicação em 23.1.2008 e na forma revisada em 23.7.2008.

2 Engo-Agro ${ }^{\circ}$, Dr., Pesquisador da Empresa de Pesquisa Agropecuária e Extensão Rural de Santa Catarina (Epagri)/Estação Experimental de Canoinhas, BR 280, km 219, Caixa Postal 216, 89460-000, <balbinot@epagri.sc.gov.br>; ${ }^{3}$ Eng $^{-}-$Agr $^{\circ}$, Dr., Professor da UFPR, Dep. de Fitotecnia e Fitossanitarismo, <anibalm@ufpr.br> e <linopeli@hotmail.com>; ${ }^{4}$ Engo-Agro ${ }^{0}$, Dr., Professor da UFPR, Dep. de Solos, <jefersondieckow@ufpr.br>; ${ }^{5}$ Eng ${ }^{0}-A g r$ o, Dr., Pesquisador da Epagri/Estação Experimental de Campos Novos, <milveiga@epagri.sc.gov.br>.

Planta Daninha, Viçosa-MG, v. 26, n. 3, p. 569-576, 2008 


\section{INTRODUÇÃO}

Na região Sul do Brasil, há várias opções economicamente viáveis para utilização dos solos agricultáveis durante o período de outubro a abril, com destaque para as culturas de soja, milho e feijão. Por outro lado, durante os meses de maio a setembro (período denominado de inverno), há carência de opções que gerem renda, sobretudo em pequenas propriedades (Brum et al., 2005). Nesse período, muitas áreas são mantidas em pousio, reduzindo a cobertura do solo e a incorporação de carbono orgânico e aumentando as infestações de plantas daninhas (Argenta et al., 2001) e as perdas de nutrientes devido à erosão.

Uma alternativa de uso do solo durante o inverno é o cultivo de espécies de coberturas, as quais podem fornecer elevada quantidade de palha para cultivos estivais em sistema de plantio direto (Ceretta et al., 2002; Giacomini et al., 2003). No entanto, as culturas de cobertura do solo não fornecem renda imediata, o que reduz seu uso em muitos casos, sobretudo quando há elevado preço de sementes. Outra alternativa é o uso das áreas no inverno com pastagens anuais, em sistema de integração lavoura-pecuária (Nicoloso et al., 2006). A integração lavoura-pecuária é um sistema de produção com alternância de pastagem e outras culturas de interesse econômico, principalmente grãos, ao longo do tempo. É um sistema que pode apresentar vantagens financeiras e biológicas (Entz et al., 2002).

Essas alternativas de uso do solo no inverno podem afetar a emergência de diásporos de plantas daninhas no início da primavera, momento em que é realizada a semeadura do mi1ho. Isso pode ocorrer porque a palha remanescente sobre o solo é diferente para cada forma de uso deste no inverno. Sabe-se que há correlação negativa entre quantidade de palha sobre o solo e infestação de plantas daninhas (Theisen et al., 2000; Vidal \& Trezzi, 2004; Balbinot Jr. et al., 2005). A palha sobre o solo dificulta a emergência e/ou crescimento de várias espécies daninhas devido ao efeito físico de sombreamento (Radosevich et al., 1997), à redução da amplitude térmica do solo (Severino \& Chistoffoleti, 2001), ao aumento da população de microrganismos que podem infectar diásporos de plantas daninhas (Radosevich et al., 1997) e à liberação de aleloquímicos (Trezzi \& Vidal, 2004; Souza et al., 2006).

Além disso, a forma de uso do solo no inverno pode afetar as suas variáveis químicas, fisicas e biológicas, que, por sua vez, podem alterar a dinâmica do banco de diásporos de espécies daninhas (Marchezan et al., 2003), devido, em especial, às alterações em umidade e aeração do solo (Jakelaitis et al., 2003). O pisoteio de bovinos pode aumentar significativamente a densidade do solo na profundidade de até $10 \mathrm{~cm}$, alterando a aeração e a retenção de água do solo (Albuquerque et al., 2001).

O objetivo deste trabalho foi avaliar o efeito de diferentes formas de uso do solo no inverno sobre a infestação de plantas daninhas na cultura de milho cultivado em sucessão, sob plantio direto.

\section{MATERIAL E MÉTODOS}

Dois experimentos foram conduzidos em propriedades particulares, na safra de 2006/ 07, na região do Planalto Norte de Santa Catarina, município de Major Vieira. As coordenadas geoprocessadas do experimento 1 foram: longitude de $50^{\circ} 18^{\prime}$, latitude de $26^{\circ} 27^{\prime}$ e altitude de $791 \mathrm{~m}$; e do experimento 2: longitude de $50^{\circ} 24^{\prime}$, de latitude $26^{\circ} 28^{\prime}$ e altitude de $822 \mathrm{~m}$. O solo dos experimentos foi classificado como Cambissolo Háplico (Embrapa, 1998).

Nos dois experimentos, o delineamento experimental utilizado foi o de blocos completos casualizados, com três repetições e tratamentos dispostos em parcelas subdivididas. Nas parcelas foram alocadas cinco formas de uso do solo no inverno: 1) consórcio de aveia-preta (Avena strigosa) + azevém (Lolium multiflorum) + ervilhaca (Vicia villosa) + trevo-vesiculoso (Trifolium vesiculosum) manejado sem pastejo e sem adubação nitrogenada (consórcio cobertura); 2) o mesmo consórcio, com pastejo e com adubação nitrogenada de cobertura - $100 \mathrm{~kg} \mathrm{ha}^{-1}$ de $\mathrm{N}($ pastagem com $\mathrm{N})$; 3) o mesmo consórcio, com pastejo e sem adubação nitrogenada (pastagem sem N); 4) nabo forrageiro (Raphanus sativus), sem pastejo e sem adubação nitrogenada (nabo forrageiro); e 5) pousio, sem pastejo e sem adubação nitrogenada (pousio). Cada parcela apresentou área total de $64 \mathrm{~m}^{2}$ $(8 \times 8 \mathrm{~m})$. Nas subparcelas foram alocadas duas situações de infestação de plantas daninhas: 
ausência e presença destas. Cada subparcela apresentou área total de $32 \mathrm{~m}^{2}(4 \times 8 \mathrm{~m})$ e área útil de $12 \mathrm{~m}^{2}(2,4 \times 5 \mathrm{~m})$.

As culturas de inverno foram implantadas no dia $22 / 5 / 2006$. As quantidades de sementes utilizadas foram as seguintes: consórcio $\left(40 \mathrm{~kg} \mathrm{ha}^{-1}\right.$ de aveia-preta $+30 \mathrm{~kg} \mathrm{ha}^{-1}$ de azevém $+30 \mathrm{~kg} \mathrm{ha}^{-1}$ de ervilhaca $+8 \mathrm{~kg} \mathrm{ha}^{-1} \mathrm{de}$ trevo-vesiculoso) e $20 \mathrm{~kg} \mathrm{ha}^{-1}$ de nabo forrageiro. As sementes de trevo-vesiculoso foram semeadas a lanço após serem escarificadas mecanicamente, inoculadas com Rhizobium leguminosarum bv. trifolii e peletizadas. Em seguida, as demais espécies foram semeadas em espaçamento entre fileiras de $17 \mathrm{~cm}$ e profundidade de aproximadamente $4 \mathrm{~cm}$.

No dia 28/6/2006, quando a aveia-preta apresentava em média dois afilhos, realizouse adubação nitrogenada no tratamento pastagem com N. A dose foi de $100 \mathrm{~kg} \mathrm{ha}^{-1}$ de $\mathrm{N}$ na forma de uréia, aplicada a lanço.

Para realizar o pastejo nos tratamentos 2 e 3, utilizaram-se duas vacas em lactação por parcela, agrupadas de modo que as unidades experimentais recebessem peso animal similar. As vacas utilizadas eram da raça Holandesa (peso de 500 a $650 \mathrm{~kg}$ cada). Antes de entrarem nas parcelas, os animais permaneceram em pastagem de aveia-preta e azevém por, no minimo, duas horas. A variável usada para determinar os momentos de entrada e saída dos animais foi a altura da pastagem. Os animais entravam nas parcelas quando a altura média era de 25 a $30 \mathrm{~cm}$ e saíam quando a pastagem apresentava altura média de $10 \mathrm{~cm}$. As parcelas com pastejo foram separadas das demais com cerca eletrificada.

Durante o ciclo de desenvolvimento da pastagem, foram feitos quatro pastejos. $\mathrm{O}$ primeiro ocorreu no dia 2/8/2006, com tempo de duração de 30 a 40 minutos. O segundo pastejo ocorreu no dia 5/9/2006 e durou de quatro a cinco horas. O terceiro pastejo ocorreu no dia 5/10/ 2006, e o tempo de duração foi de cinco a seis horas. O quarto pastejo ocorreu nos dias 23/ 10/2006 (experimento 2) e 25/10/2006 (experimento 1), com duração de cinco a seis horas.

No dia $31 / 10 / 2006$, realizou-se a dessecação das plantas contidas em todos os tratamentos. Para isso, utilizou-se glyphosate (1.440 $\left.\mathrm{g} \mathrm{ha}^{-1}\right)$ e óleo mineral $\left(1,5 \mathrm{~L} \mathrm{ha}^{1}\right)$, aplicados com pulverizador costal.

O milho foi semeado no dia $8 / 11 / 2006$. Os dois experimentos foram implantados com semeadora contendo facão para abrir o sulco, com profundidade aproximada de $12 \mathrm{~cm}$. No experimento 1 , a adubação de base foi de 30,135 e $70 \mathrm{~kg} \mathrm{ha}^{-1}$ de N, $\mathrm{P}_{2} \mathrm{O}_{5}$ e $\mathrm{K}_{2} \mathrm{O}$ e, no experimento 2, de 30, 105 e $70 \mathrm{~kg}^{-1}$ de $\mathrm{N}, \mathrm{P}_{2} \mathrm{O}_{5}$ e $\mathrm{K}_{2} \mathrm{O}$, respectivamente. Nos dois ensaios, utilizou-se o híbrido Dekalb 214, cultivado em espaçamento de $0,8 \mathrm{~m}$ entre fileiras e $60 \mathrm{mil}$ plantas $\mathrm{ha}^{-1}$. O controle de plantas daninhas nas subparcelas livres de infestação foi realizado com os herbicidas atrazine ( $1.500 \mathrm{~g}$ i.a. ha $\left.{ }^{-1}\right)$ e nicosulfuron (40 g i.a. ha-1). No dia 13/12/2006 foram aplicados, a lanço, $70 \mathrm{~kg}^{-1}$ de $\mathrm{N}$ em cobertura, na forma de uréia.

Foram avaliados: a quantidade de palha remanescente dos tratamentos de inverno, por meio de coleta da palha presente em amostra de $1 \mathrm{~m}^{2}$ por subparcela; a densidade de plantas daninhas aos 35 dias após a semeadura (DAS) do milho, por meio de amostragem de dois pontos de $0,25 \mathrm{~m}^{2}$ por subparcela infestada, que representava a infestação da subparcela; a massa seca de plantas daninhas aos 100 DAS, por meio de amostragem de $0,25 \mathrm{~m}^{2}$ por subparcela infestada; o número de espigas por planta, avaliado pela contagem de plantas e espigas contidas na área útil das subparcelas $\left(12 \mathrm{~m}^{2}\right)$; o número estimado de grãos por espiga, tomando-se como base a relação existente entre a massa de mil grãos, a massa de grãos da subparcela e o número de espigas colhidas por subparcela; a massa média de grãos, avaliada por meio de pesagem de mil grãos por subparcela; e a produtividade de grãos de milho (corrigida para $13 \%$ de umidade), avaliada pela colheita das espigas contidas na área útil das subparcelas. Realizou-se a análise conjunta dos dados, os quais foram submetidos à análise de variância e ao teste F; quando constatados efeitos significativos de tratamentos, as médias foram comparadas pelo teste de Tukey a $5 \%$. Os dados de densidade de plantas daninhas foram transformados em $\mathrm{y}=\sqrt{x+1}$ para atender às pressuposições da análise de variância.

\section{RESULTADOS E DISCUSSÃO}

Para a variável quantidade de palha remanescente sobre o solo, houve interação 
significativa entre tratamentos e experimentos. No experimento 2, o tratamento consórcio cobertura (aveia-preta + azevém + ervilhaca + trevo-vesiculoso) proporcionou a maior quantidade de palha para a cultura de milho (Tabela 1). Já no experimento 1, menor quantidade de palha foi verificada no tratamento com cobertura de nabo forrageiro; os demais tratamentos não diferiram entre si. Nos dois experimentos, houve emergência espontânea de plantas de inverno no tratamento pousio, as quais permaneceram na área. No experimento 1 a palha presente no tratamento pousio era composta basicamente por azevém e, no experimento 2, por azevém e trevos branco (Trifolium repens) e vermelho (T. pratense). No experimento 2, o consórcio cobertura produziu mais palha do que no experimento 1 . Contudo, nos tratamentos com pastagens, a palha remanescente foi maior no experimento 1 do que no 2 (Tabela 1$)$.

Tabela 1 - Quantidade de palha remanescente sobre o solo $\left(\mathrm{Mg} \mathrm{ha}^{-1}\right)$ em diferentes tratamentos de inverno antecedendo a cultura de milho, em dois experimentos realizados em Major Vieira, Planalto Norte de SC. Epagri, 2006

\begin{tabular}{|c|c|c|}
\hline \multirow{2}{*}{ Tratamento de inverno } & \multicolumn{2}{|c|}{ Experimento } \\
\hline & 1 & 2 \\
\hline Consórcio cobertura & $2,91 \mathrm{a}^{\mathrm{a}^{1 /}} \mathrm{B}^{1 / /}$ & 4,97 a A \\
\hline Pastagem com $\mathrm{N}$ & 2,42 a A & $0,47 \mathrm{~b} \mathrm{~B}$ \\
\hline Pastagem sem N & 1,80 a $\mathrm{A}$ & $0,49 \mathrm{~b} \mathrm{~B}$ \\
\hline Nabo forrageiro & $0,19 \mathrm{~b} \mathrm{~A}$ & $0,77 \mathrm{~b} \mathrm{~A}$ \\
\hline Pousio & 2,40 a A & $1,69 \mathrm{~b} \mathrm{~A}$ \\
\hline $\mathrm{CV}(\%)$ & \multicolumn{2}{|c|}{38,1} \\
\hline
\end{tabular}

${ }^{1 /}$ Médias seguidas da mesma letra, minúsculas nas colunas e maiúsculas nas linhas, não diferem entre si pelo teste de Tukey a $5 \%$.

Durante o ciclo de desenvolvimento da cultura de milho, as principais plantas daninhas presentes nos experimentos foram: papuã (Brachiaria plantaginea), guanxuma (Sida spp.) e milhã (Digitaria spp.). Quanto às variáveis densidade de plantas daninhas aos 35 dias após a semeadura (DAS) do milho e acúmulo de massa pelas plantas daninhas avaliado aos 100 DAS, não houve interação significativa entre experimentos e tratamentos. Na média dos dois experimentos, o uso do solo no inverno com o consórcio cobertura, manejado sem pastejo e sem adubação nitrogenada, proporcionou menores densidades e acúmulo de massa pelas plantas daninhas em relação aos demais tratamentos, porém não diferiu significativamente do tratamento pousio (Tabela 2).

Tabela 2 - Densidade de plantas daninhas aos 35 dias após a semeadura (DAS) do milho e massa seca de plantas daninhas aos 100 DAS, em diferentes tratamentos de inverno antecedendo a cultura (média de dois experimentos). Major Vieira, Planalto Norte de SC. Epagri, 2006/07

\begin{tabular}{|c|c|c|}
\hline $\begin{array}{c}\text { Tratamento de } \\
\text { inverno }\end{array}$ & $\begin{array}{c}\text { Densidade de plantas } \\
\text { daninhas aos 35 DAS } \\
\left(\text { plantas m}^{-2}\right)\end{array}$ & $\begin{array}{c}\text { Massa seca de plantas } \\
\text { daninhas aos } \\
100 \text { DAS }\left(\mathrm{g} \mathrm{m}^{-2}\right)\end{array}$ \\
\hline Consórcio cobertura & $213^{2^{2 /}} \mathrm{b}^{\underline{1}}$ & $46,5 \mathrm{~b}$ \\
\hline Pastagem com $\mathrm{N}$ & $587 \mathrm{a}$ & $132,0 \mathrm{a}$ \\
\hline Pastagem sem N & $513 \mathrm{a}$ & $110,2 \mathrm{a}$ \\
\hline Nabo forrageiro & $510 \mathrm{a}$ & $113,0 \mathrm{a}$ \\
\hline Pousio & $350 \mathrm{ab}$ & $79,5 \mathrm{ab}$ \\
\hline $\mathrm{CV}(\%)$ & 20,1 & 36,9 \\
\hline
\end{tabular}

1/Médias seguidas das mesmas letras nas colunas não diferem entre si pelo teste de Tukey a $5 \%$.

2/ Aplicou-se a transformação $\mathrm{y}=\sqrt{x+1}$ antes da análise. Os dados são apresentados em escala original

O consórcio cobertura (aveia-preta + azevém + ervilhaca + trevo-vesiculoso) proporcionou elevada supressão de plantas daninhas na cultura do milho semeada em sucessão porque deixou sobre o solo elevada quantidade de palha (Tabela 1). O pousio também proporcionou alta supressão de emergência e acúmulo de massa pelas plantas daninhas porque houve crescimento espontâneo de azevém neste tratamento. A palha de azevém possui elevado potencial em suprimir a emergência e o crescimento de plantas daninhas estivais (Balbinot Jr. et al., 2005). Os tratamentos com pastagens de inverno, com e sem adubação nitrogenada, bem como a cobertura do solo com nabo forrageiro, permitiram elevada infestação de plantas daninhas de verão (Tabela 2), pois forneceram baixa quantidade de palha para cobertura do solo (Tabela 1 ). O pisoteio animal nos tratamentos com pastagens de inverno pode ter aumentado o contato dos diásporos de plantas daninhas com o solo, o que pode ter incrementado a emergência de plantas daninhas estivais. Além disso, a palha de nabo forrageiro apresenta baixo potencial em suprimir a emergência e o crescimento de plantas daninhas, uma vez que se decompõe rapidamente (Balbinot Jr. et al., 2005). Constatou-se que a adubação nitrogenada da pastagem de inverno 
não afetou a emergência e o acúmulo de massa pelas plantas daninhas estivais.

O número de grãos por espiga e a massa do grão foram afetados pela situação de infestação de plantas daninhas. Sob interferência de plantas daninhas, o número de grãos por espiga e a massa do grão foram inferiores à situação de ausência de interferência dessas plantas (Tabela 3). Isso ocorreu devido à competição pelos recursos do meio imposta pelas plantas daninhas, reduzindo a disponibilidade de água, luz e nutrientes para a cultura do milho. A massa do grão também foi afetada pelos tratamentos de inverno. Na média dos dois experimentos e das duas situações de infestação, o consórcio cobertura permitiu a formação de grãos com maior massa, comparativamente ao pousio no inverno (Tabela 4).

A produtividade de grãos de milho não foi afetada significativamente pelos tratamentos de inverno (Tabela 5). Dessa forma, não houve efeito residual da adubação nitrogenada da pastagem de inverno para a cultura de milho.

Tabela 3 - Número de grãos por espiga de milho e massa do grão em duas situações de infestação de plantas daninhas (média de dois experimentos e cinco tratamentos de inverno antecedendo a cultura). Major Vieira, Planalto Norte de SC. Epagri, 2007

\begin{tabular}{|l|c|c|}
\hline Situação de infestação & $\begin{array}{c}\text { Número de grãos } \\
\text { por espiga }\end{array}$ & $\begin{array}{c}\text { Massa de mil grãos } \\
(\mathrm{g})\end{array}$ \\
\hline Sem plantas daninhas & $479 \mathrm{a}^{\underline{1}}$ & $375 \mathrm{a}$ \\
\hline Com plantas daninhas & $446 \mathrm{~b}$ & $366 \mathrm{~b}$ \\
\hline CV $(\%)$ & 6,9 & 3,2 \\
\hline
\end{tabular}

${ }^{1 /}$ Médias seguidas das mesmas letras nas colunas não diferem entre si pelo teste de Tukey a $5 \%$.

Tabela 4 - Massa de grãos de milho em diferentes tratamentos de inverno antecedendo a cultura (média de dois experimentos e de duas situações de infestação de plantas daninhas). Major Vieira, Planalto Norte de SC. Epagri, 2007

\begin{tabular}{|c|c|}
\hline Tratamento de inverno & Massa de mil grãos $(\mathrm{g})$ \\
\hline Consórcio cobertura & $378 \mathrm{a}^{\underline{\underline{1}}}$ \\
\hline Pastagem com N & $374 \mathrm{a}$ \\
\hline Pastagem sem N & $371 \mathrm{ab}$ \\
\hline Nabo forrageiro & $370 \mathrm{ab}$ \\
\hline Pousio & $359 \mathrm{~b}$ \\
\hline $\mathrm{CV}(\%)$ & 3,2 \\
\hline
\end{tabular}

1/ Médias seguidas das mesmas letras nas colunas não diferem entre si pelo teste de Tukey a $5 \%$.
Tabela 5 - Produtividade de grãos de milho em duas situações de infestação de plantas daninhas e redução média de produtividade de grãos em razão da interferência de plantas daninhas em diferentes tratamentos de inverno antecedendo a cultura (média de dois experimentos). Major Vieira, Planalto Norte de SC. Epagri, 2007

\begin{tabular}{|c|c|c|c|}
\hline \multirow{2}{*}{$\begin{array}{l}\text { Tratamento de } \\
\text { inverno }\end{array}$} & \multicolumn{2}{|c|}{$\begin{array}{l}\text { Produtividade de grãos } \\
\qquad\left(\mathrm{kg} \mathrm{ha}^{-1}\right)\end{array}$} & \multirow{2}{*}{$\begin{array}{c}\text { Redução de } \\
\text { produtividade } \\
\text { (\%) }\end{array}$} \\
\hline & $\begin{array}{c}\text { Sem } \\
\text { plantas } \\
\text { daninhas }\end{array}$ & $\begin{array}{c}\text { Com } \\
\text { plantas } \\
\text { daninhas }\end{array}$ & \\
\hline Consórcio cobertura & $10.986 \mathrm{a}^{\frac{1}{}}$ & $10.414 \mathrm{a}$ & 5,2 \\
\hline Pastagem com N & $11.465 \mathrm{a}$ & $10.009 \mathrm{a}$ & 12,7 \\
\hline Pastagem sem N & $11.079 \mathrm{a}$ & $10.104 \mathrm{a}$ & 8,8 \\
\hline Nabo forrageiro & $11.697 \mathrm{a}$ & $10.188 \mathrm{a}$ & 12,9 \\
\hline Pousio & $11.187 \mathrm{a}$ & $9.900 \mathrm{a}$ & 11,5 \\
\hline Médias & $11.283 \mathrm{~A}^{1}$ & $10.123 \mathrm{~B}$ & 10,1 \\
\hline CV (\%) & \multicolumn{2}{|c|}{7,6} & \\
\hline
\end{tabular}

1/ Médias seguidas das mesmas letras, minúsculas nas colunas e maiúsculas nas linhas, não diferem entre si pelo teste de Tukey a $5 \%$.

Possivelmente, esse resultado seja decorrente da elevada precipitação pluvial que ocorreu entre os meses de setembro e novembro (Figuras 1 e 2), o que pode ter provocado lixiviação de grande parte do $\mathrm{N}$ aplicado na pastagem de inverno, indisponibilizando-o à cultura de milho. Por outro lado, em trabalho realizado por Assmann et al. (2003), constatou-se efeito residual da adubação nitrogenada da pastagem de inverno sobre a cultura de milho semeada em sucessão.

Houve efeito da situação de infestação sobre a produtividade de grãos de milho (Tabela 5). Sob interferência de plantas daninhas, a produtividade de grãos de milho foi cerca de $10 \%$ inferior à situação de ausência de interferência. Devido à menor infestação de plantas daninhas na cultura de milho sobre palha do consórcio cobertura (Tabela 2), a redução de produtividade de grãos de milho em virtude da interferência exercida pelas plantas daninhas foi menor neste tratamento em relação aos demais (Tabela 5). Isso demonstra a importância da manutenção do solo coberto com palha para o manejo cultural de plantas daninhas em sistema de plantio direto, fato esse já observado e discutido por Theisen et al. (2000) e Trezzi \& Vidal (2004).

Percebe-se que, em sistema de integração lavoura no verão e pecuária no inverno, há

Planta Daninha, Viçosa-MG, v. 26, n. 3, p. 569-576, 2008 


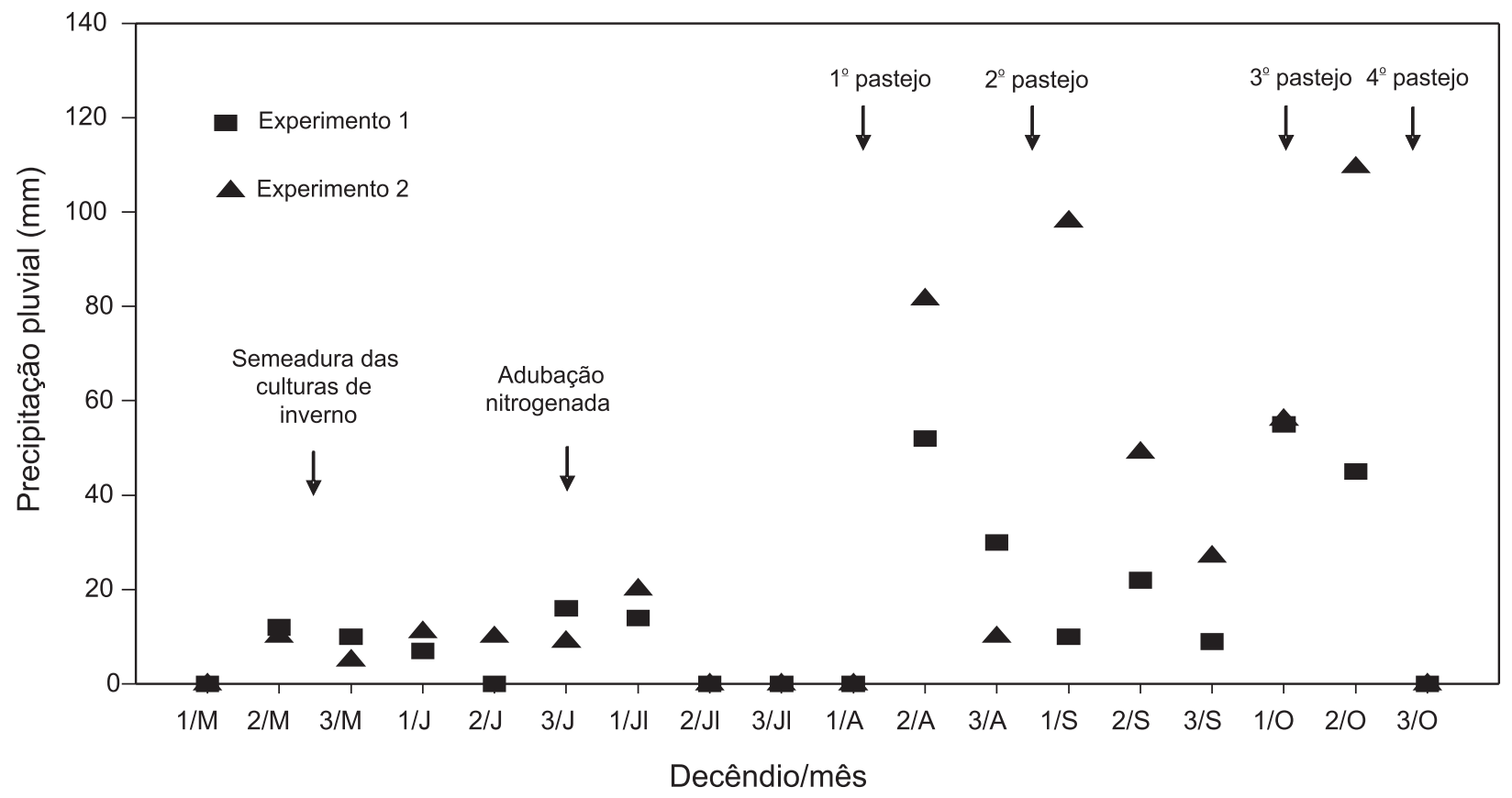

Figura 1 - Precipitação pluvial entre o primeiro decêndio de maio e o terceiro decêndio de outubro de 2006, em dois experimentos realizados em Major Vieira, Planalto Norte de SC. Epagri, 2006.

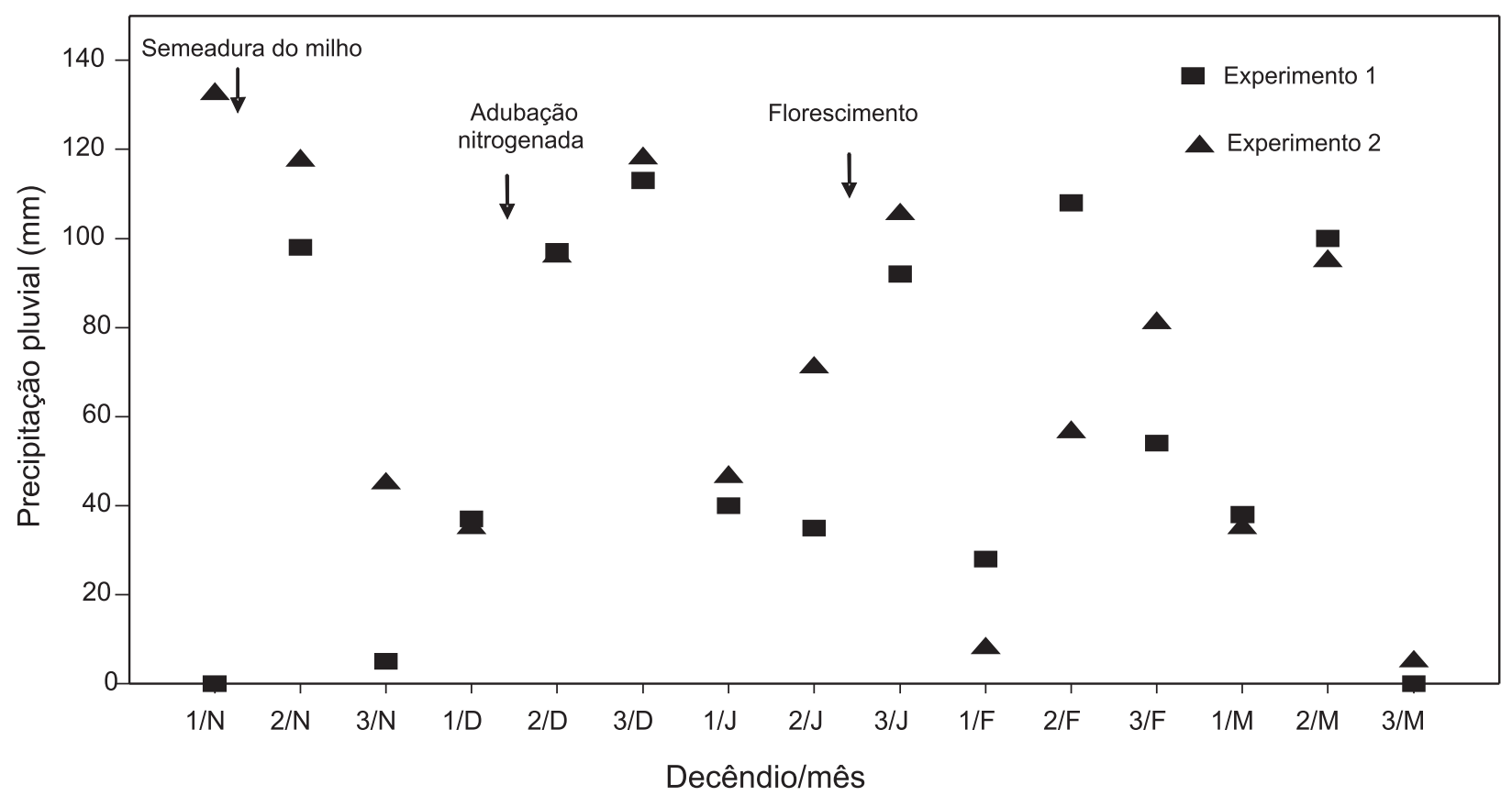

Figura 2 - Precipitação pluvial entre o primeiro decêndio de novembro de 2006 e o terceiro decêndio de março de 2007, em dois experimentos conduzidos em Major Vieira, Planalto Norte de SC. Epagri, 2006/07. 
pequena quantidade de palha remanescente para proteção do solo no verão, pois grande parte da massa vegetal produzida pela pastagem é consumida pelos animais. A reduzida quantidade de palha neste sistema pode aumentar a infestação de plantas daninhas ao longo do tempo. Segundo Ceretta et al. (2002), um dos alicerces do sistema de plantio direto é a manutenção do solo coberto durante todo o ano. Nesse sentido, em áreas infestadas com plantas daninhas estivais é importante manejar a pastagem de inverno de forma que haja sobra de palha para proteção do solo no verão. Salienta-se que o cultivo de pastagens no inverno pode gerar renda em decorrência da produção de carne e/ou leite, além de proporcionar vantagens biológicas, como melhoria das propriedades químicas e biológicas do solo, quando o sistema é manejado adequadamente (Entz et al., 2002).

Nesse contexto, na região Sul do Brasil, a utilização do solo no inverno com consórcio de espécies para cobertura do solo, sem pastejo, permite alta produção de palha para proteção do solo no verão, reduzindo a infestação de plantas daninhas na cultura de milho semeada em sucessão. Por outro lado, nas condições em que foi realizado o trabalho, o uso do solo no inverno com pastagens anuais e com cobertura de nabo forrageiro permite elevada infestação de plantas daninhas na cultura de milho.

\section{AGRADECIMENTOS}

Aos produtores rurais Amélio Gudas, Danilo Guedes e Ivo Grein, pela participação nos trabalhos de pesquisa.

\section{LITERATURA CITADA}

ALBUQUERQUE, J. A.; SANGOI, L.; ENDER, M. Efeitos da integração lavoura-pecuária nas propriedades físicas do solo e características da cultura do milho. R. Bras. Ci. Solo, v. 25, n. 3 , p. $717-723,2001$.

ARGENTA, G. et al. Efeitos do manejo mecânico e químico da aveia-preta no milho em sucessão e no controle do capimpapuã. Pesq. Agropec. Bras., v. 36, n. 6, p. 851-860, 2001.

ASSMANN, T. S. et al. Rendimento de milho em área de integração lavoura-pecuária sob o sistema plantio direto, em presença e ausência de trevo branco, pastejo e nitrogênio. R. Bras. Ci. Solo, v. 27, n. 4, p. 675-683, 2003.
BALBINOT JR., A. A.; BIALESKI, M.; BACKES, R. L. Épocas de manejo de plantas de cobertura do solo de inverno e incidência de plantas daninhas na cultura do milho. Agropec. Catarinense, v. 18, n. 3, p. 91-94, 2005.

BRUM, A. L. et al. A competitividade do trigo brasileiro diante da concorrência argentina. O comércio internacional e a competitividade pelo custo de produção. R. Galega Econ. v. 14, n. 1-2, p. 1-15, 2005.

CERETTA, C. A. et al. Produção e decomposição de plantas invernais de cobertura de solo e milho, sob diferentes manejos da adubação nitrogenada. Ci. Rural, v. 32, n. 1, p. 49-54, 2002.

EMPRESA BRASILEIRA DE PESQUISA AGROPECUÁRIA - EMBRAPA. Centro Nacional de Pesquisa de Solos. Mapa de solos do Estado de Santa Catarina. 1998. Disponível em: <http://200.20.158.13/ website/pub/Santa_Catarina $>$. Acesso em: 22 de jun. de 2007.

ENTZ, M. H. et al. Potential of forages to diversify cropping systems in the Northern Great Plains. Agron. J., v. 94, n. 1, p. 204-213, 2002.

GIACOMINI, S. J.; AITA, C.; VENDRUSCOLO, E. R. O. Matéria seca, relação $\mathrm{C} / \mathrm{N}$ e acúmulo de nitrogênio, fósforo e potássio em misturas de plantas de cobertura de solo.

R. Bras. Ci. Solo, v. 27, n. 2, p. 325-334, 2003.

JAKELAITIS, A. et al. Dinâmica populacional de plantas daninhas sob diferentes sistemas de manejo nas culturas de milho e feijão. Planta Daninha, v. 21, n. 1, p. 71-79, 2003.

MARCHEZAN, E. et al. Dinâmica do banco de sementes de arroz-vermelho afetado pelo pisoteio bovino e tempo de pousio da área. Planta Daninha, v. 21, n. 1, p. 55-62, 2003.

NICOLOSO, R. S.; LANZANOVA, M. E.; LOVATO, T. Manejo das pastagens de inverno e potencial produtivo de sistemas de integração lavoura-pecuária no Estado do Rio Grande do Sul. Ci. Rural, v. 36, n. 6, p. 1799-1805, 2006.

RADOSEVICH, S.; HOLT, J.; GHERSA, C. Weed ecology: implications for management. 2.ed. New York: Wiley, 1997. $588 \mathrm{p}$.

SEVERINO, F. J.; CHRISTOFFOLETI, P. J. Efeitos de quantidades de fitomassa de adubos verdes na supressão de plantas daninhas. Planta Daninha, v. 19, n. 2, p. 223-228, 2001.

Planta Daninha, Viçosa-MG, v. 26, n. 3, p. 569-576, 2008 
SOUZA, L. S. et al. Efeito alelopático de capim-braquiária (Brachiaria decumbens) sobre o crescimento inicial de sete espécies de plantas cultivadas. Planta Daninha, v. 24, n. 4, p. $657-668,2006$

THEISEN, G.; VIDAL, R. A.; FLECK, N. G. Redução da infestação de Brachiaria plantaginea em soja pela cobertura do solo com palha de aveia-preta. Pesq. Agropec. Bras., v. 35, n. 4 , p. $753-756,2000$.
TREZZI, M. M.; VIDAL, R. A. Potencial de utilização de cobertura vegetal de sorgo e milheto na supressão de plantas daninhas em condição de campo: II - Efeitos da cobertura morta. Planta Daninha, v. 22, n. 1, p. 1-10, 2004.

VIDAL, R. A.; TREZZI, M. M. Potencial da utilização de coberturas vegetais de sorgo e milheto na supressão de plantas daninhas em condição de campo: I. Plantas em desenvolvimento vegetativo. Planta Daninha, v. 22, n. 2, p. $217-223,2004$ 